\title{
VIOLÊNCIA E INTERPRETAÇÃO, LEITURAS DA HISTÓRIA DE MACAU
}

\author{
VIOLENCE AND INTERPRETATION, \\ READINGS OF THE HISTORY OF MACAU
}

Mário César Lugarinho ${ }^{1}$

\section{RESUMO}

O artigo apresenta a leitura de duas narrativas a respeito do assassinato do governador português de Macau, João Maria Ferreira do Amaral, em 1849. Uma escrita no contexto histórico do Estado Novo (1943) e outra, bem mais recente (2015), já escrita após o handover. A partir delas, é possível perceber o conflito entre culturas que disputam a memória do território.

PALAVRAS-CHAVE: Macau; história; memória.

\section{ABSTRACT}

The article presents the reading of two narratives about the assassination of the Portuguese governor of Macau, Ferreira do Amaral, in 1849. The first narrative was written in the historical context of Estado Novo (1943) and the second one, much more recent (2015), written after the handover. From them, it is possible to perceive the conflict between cultures that dispute the memory of the territory.

KEYWORDS: Macao; history; memory. 


\section{ESPAÇO}

O território de Macau, hoje, parte integrante da República Popular da China, sob o estatuto de Região Administrativa Especial, similar a Hong Kong, foi parte constitutiva do Império Colonial Português, segundo a tradição historiográfica, de 1557 a 1999, a mais longa ocupação colonial em território chinês. No entanto, não há consenso a respeito de sua história e memória, na medida em que apenas em 1887, o tratado sino-português reconheceu a efetiva soberania portuguesa sobre o território. Antes disso, por tradição, experimentou uma governança compartilhada entre seu governador geral, o Leal Senado, ${ }^{2}$ e o mandarinato local, que devia obediência ao governador de Cantão; em termos econômicos, cabia, porém, à Coroa portuguesa explorar uma alfândega específica, enquanto que cabia aos mandarins de Macau e Cantão explorarem uma alfândega chinesa.

Em 1842, após a Guerra do Ópio (1839-1842), os britânicos ocuparam a atual região de Hong Kong, situada a algumas dezenas de quilômetros da possessão portuguesa, não sem, antes, terem cobiçado a pequena península onde Macau se situa. Hong Kong prosperou rapidamente a ponto de o comercio com Macau ter entrado em rápido declínio, levando ao fim a contínua prosperidade, garantida desde o século XVI, do diminuto território de $14 \mathrm{~km}^{2}$.

A Coroa portuguesa, em 1845, a fim de reagir à concorrência britânica, tomou algumas decisões que definiriam o futuro da pequena cidade. Dentre essas medidas, estabeleceu que a principal autoridade administrativa era o governador geral do território, esvaziando a autoridade do Leal Senado; submeteu o território à administração direta de Lisboa, que, até então, fora intermediada por Goa; declarou Macau porto franco; e, como medida mais importante e problemática, unificou as alfândegas portuguesa e chinesa, sob a administração portuguesa. Para tanto, nomeou João Maria Ferreira do Amaral (1803-1849) como governador geral de Macau a fim de levar a efeito aquelas decisões.

Iniciando a sua administração em 1846, após sua chegada ao Oriente, Ferreira do Amaral não alcançou a simpatia dos grupos que tradicionalmente dominaram o território já que governou com o firme propósito de cumprir as determinações da Coroa que levara consigo. Veio a ser assassinado, em 1849, enquanto passava, a cavalo, próximo aos limites do território. A memória de sua passagem por Macau e, consequentemente, de seu assassinato não foi apagada pelo tempo.

Em 1940, dentro das comemorações dos centenários portugueses, a administração colonial de Macau, num esforço de urbanização, inaugurou a Praça Ferreira do Amaral, em cujo centro foi erigida uma grande estátua em homenagem e reconhecimento ao antigo governador. É uma estátua equestre, colocada sobre um imenso pedestal. O governador está representado sobre o cavalo, levantado, e em posição de luta, brandindo 
um chicote; abaixo do cavalo, sob suas patas, estão chineses amontoados com feições amedrontadas. A estátua possui proporções grandiosas e o realismo da cena fixada chama a atenção pela violência que nela está representada. Enquanto a soberania do território foi exercida pelos portugueses, a comunidade chinesa usou como denominação para a praça, em cantonês, "Praça do Cavalo de Bronze".

A praça, como logradouro, fica localizada numa área urbana, hoje, bastante importante para a cidade de Macau. Nela se encontram um terminal rodoviário urbano, o edifício-sede do Bank of China, em Macau, o imponente edifício do Hotel e Cassino Grand Lisboa e, em proporções menores, o Hotel e Cassino Lisboa, que remonta a década de 1950. Nessa área urbana está resumida uma narrativa da história macaense dos últimos duzentos anos. Desde o nome da praça, Ferreira do Amaral, até a localização do Bank of China, passando por ambos os hotéis e cassinos, além da proximidade da Ponte Governador Nobre de Carvalho, que liga Macau à ilha de Taipa. Ao ser inaugurada a praça, a região era pouco habitada, mas já indicava que seria local privilegiado para ocupação, dada a expansão econômica que a então colônia portuguesa experimentava naquela altura, tanto em função da cooperação com Hong Kong, quanto pelo incremento dos cassinos, que começavam a florescer como robusta atividade econômica para a cidade.

O acordo entre a República Popular da China e a República Portuguesa, de 1987, que acertou a devolução de Macau aos chineses para dezembro de 1999, estabeleceu um gradativo processo de autonomia. Nos anos seguintes, sucessivos governos formados por membros, em sua maioria, da comunidade chinesa do território passaram a exercer a sua administração.

Em 1992, a estátua do governador Ferreira do Amaral foi devidamente retirada do centro da praça e devolvida a Portugal. Atualmente, o monumento, desprovido de seu grandioso pedestal encontra pouso no Jardim da Encarnação, em Lisboa. Em Macau, o nome praça foi mantido, em português, e a sua denominação anterior, em cantonês, foi substituída pela transcrição do nome português para o cantonês, entretanto, no lugar antes ocupado pela estátua, há apenas um jardim que cobre um estacionamento subterrâneo. Além disso, o jardim encontra-se à sombra do grandioso edifício do hotel e cassino Grand Lisboa, cuja forma, atípica relembra a flor de lótus, símbolo máximo da cidade.

A história da praça, que culmina com a retirada da estátua, bem constitui uma narrativa que metonimiza a história de Macau do último século, na medida em que o handover ${ }^{3}$ acendeu um debate acerca da identidade cultural da região. Seria Macau inteiramente chinesa ou portuguesa? $\mathrm{Ou}$ os mais de quatrocentos anos de presença portuguesa teriam gerado uma cultura autônoma? E essa cultura autônoma seria mais portuguesa ou chinesa, ${ }^{4}$ ou vice-versa? Macau teria criado uma cultura completamente autônoma? A narrativa urbanística oferece algum sentido e algumas lições a quem se dedica a estas questões por demonstrar um hesitante processo de 
denegação do passado colonial; ora, a devolução da estátua do governador indicaria o desejo de superação desse passado, como se ostensivamente a nova administração chinesa, em 1992, enviasse um evidente informe à história e ao futuro do território. Entretanto, após o handover, é visível o esforço da administração de Macau em preservar a memória colonial, tanto pela manutenção, mesmo que apenas oficialmente, da língua portuguesa como língua do território, quanto pela preservação de monumentos históricos, nomes de logradouros e, principalmente, ações específicas, nos campos econômico, educacional e cultural, de divulgação da língua, bem como de aproximação com a Comunidade dos Países de Língua Portuguesa (CPLP). ${ }^{5}$

\section{A MEMÓRIA DO ASSASSINADO}

Assim, se aquela narrativa urbanística é metonímia da história macaense, ao seu lado a literatura ${ }^{6}$ voltou a sua atenção à biografia do governador assassinado. Em 2015, foi publicado $O$ assassino, conto do jovem autor cantonês Joe Tang, em versão trilingue (português, inglês e cantonês), que apresenta três narrativas sobre o assassinato do governador: a que acompanha o governador de Cantão, outra que acompanha o governador português de Macau e aquela que acompanha o seu suposto assassino. A novidade da narrativa de Tang encontra-se na forma como que o crime é narrado, sobretudo, porque a narrativa se desenvolve a partir de ponto de vista diverso àquele que a história portuguesa havia fixado.

À primeira vista, $O$ assassino poderia ser pensado como uma mera versão chinesa para o episódio, certamente. Entretanto, essa expectativa é traída, já que estão postos em confronto o ambicioso governador de Cantão, Xu Guangjing e o combativo governador português de Macau, Ferreira do Amaral, e, entre eles, o assassino propriamente dito, Sheng Zhiliang.

Após o fim da narrativa, à guisa de apêndice, é encontrado um guia cronológico dedicado ao leitor desavisado. A rápida lista de fatos e datas principia em 1849, ano do assassinato de Ferreira do Amaral, e se encerra no ano de 1999, respectivamente, quando se dá a retomada da soberania chinesa sobre Macau. A referida cronologia informa da devolução da estátua a Portugal, em 28 de outubro de 1992.

O assassino, todavia, faz, da história, narrativa literária, não para contradizer o evento, mas para destacar o conflito entre pontos de vista díspares. Ao fim da narrativa fica evidente que a disputa por Macau não se encontra no real da História ou das relações humanas, mas nos seus aspectos discursivos (literários ou historiográficos). A narrativa aponta para terreno além da referencialidade historiográfica, aponta para a memória, discurso que, apesar de se construir a partir e em torno de elementos referenciais, é continuamente submetido às particularidades das subjetividades que o enunciam, visto que o assassinato, na perspectiva de Tang, acabou por se tornar vantajoso para todos os agentes históricos nele envolvidos, inclusive à vítima e ao seu algoz, condenado à morte. O governador de Cantão recebeu o reconhecimento do Imperador, especialmente por apaziguar a coroa 
portuguesa com a solução do crime e a condenação do acusado; o governador de Hong Kong acabou por ter sua honra e prestigio recuperados, além de ter garantido definitivamente à colônia britânica a supremacia econômica na região; a comunidade chinesa de Macau teve seus ganhos mantidos na medida em que a alfândega chinesa manteve seu funcionamento, até 1887; ao assassino foi garantida subsistência a sua família, algo que ele, particularmente, nunca viria a fornecer; e, ao governador assassinado, sua memória foi garantida à posteridade.

A narrativa de Tang leva-nos a perceber um consenso, construído a posteriori, sobre a morte do governador na medida em que o autoritarismo e a violência, seu resultado, fazem mudar de lugar vítima e algoz, consoante o ponto de vista, histórico, social e cultural, do observador. O procedimento da narrativa de Tang leva-nos a recorrer à seguinte observação de Andreas Huyssen:

As contrastantes e cada vez mais fragmentadas memórias políticas de grupos sociais e étnicos específicos permitem perguntar se ainda é possível, nos dias de hoje, a existência de formas de memória consensual coletiva e, em caso negativo, se e de que forma a coesão social e cultural pode ser garantida sem ela. (HUYSSEN, 2000, p. 19)

A referência e, por que não dizer, deferência, a Huyssen deve-se à constatação, apresentada em seu livro, de que, com a profusão de discursos ancorados e amparados pela memória, desde os mais midiáticos às mais aprofundadas reflexões acadêmicas, ela constituiu-se como um objeto, ou melhor, um espaço ou território disputado pelos diversos sujeitos que a compartilham de alguma maneira. No caso, não apenas os agentes envolvidos diretamente ou indiretamente no crime, mas, também, toda a comunidade macaense e, por que não dizer, as nações nela envolvidas (China, Portugal e Grã-Bretanha), todas, com suas pretensões imperiais, disputando a influência no território. Além disso, o tempo presente recebe do evento influxos de sentido que o problematizam por recuperar a narrativa do assassinato, cujos fragmentos se encontram nos três capítulos do conto.

Voltando a Huyssen (2000), a memória, com o advento das inúmeras tecnologias de arquivamento, deixou de ser patrimônio de uma geração ou de uma comunidade específica para ser posse de populações, de extensos grupos sociais, de instituições públicas e privadas e, também, principalmente, de estados, que deixaram de se contentar apenas com a história narrada por seus documentos e historiografia. O que nos leva a depreender que essa disputa pela memória, na verdade, indica a disputa pelos sentidos que constituem a História. Contudo, o que num ambiente democrático poderia ser salutar, num ambiente de autoritarismo torna-se disputa entre aqueles que se apossam dos dispositivos discursivos e que, a partir deles, definem o sentido das histórias e das historiografias - a posse desses sentidos, nos estados modernos, define as estruturas e as práticas do Direito e da Justiça, caracterizando o Estado, autoritário ou democrático. 
A narrativa de Tang, dessa forma, aquece um debate sobre o sentido da História de Macau e da forma como aquele evento foi fixado, principalmente, na historiografia portuguesa. Porque a vítima não era uma vítima qualquer, não era um burocrata a serviço da Coroa portuguesa numa terra exótica e pouco hospitaleira aos estrangeiros. Ferreira do Amaral, ao ser convocado por D. Maria II para o governo de Macau, já era celebrado pelo exército português e, por isso, considerado capacitado à áspera tarefa administrativa do território.

A nomeação do governador ocorre num momento bastante particular da história portuguesa do século XIX, quando o estado português estava a se remodelar pelo liberalismo característico daquele tempo e pelos modernos nacionalismos que davam estrutura aos estados europeus. Dessa forma, tendo em vista a sua biografia registrada, o governador já poderia ser considerado um herói vivo da nação portuguesa, cuja fama certamente o alçaria ao panteão nacional, como mais tarde aconteceria com Mouzinho de Albuquerque, ${ }^{7}$ não fosse a sua morte prematura. Após sua morte, a breve passagem de Ferreira do Amaral pelo governo de Macau pareceu cair no esquecimento da nação.

Por que insistir no herói ou, melhor, no caráter heroico das biografias e das memórias? Porque há um consenso entre historiadores e estudiosos do discurso memorialista que, nas histórias nacionais, o herói é polo atrativo de forças de inspiração e resistência para a nação. E interessa aqui a reconstrução de sua biografia nos moldes heroicos nacionais - o que acontecerá apenas durante o Estado Novo, com a inauguração de sua estátua, em 1940, e com a publicação de sua biografia, composta por uma bisneta, Lia Ferreira do Amaral, e publicada pela Agência Geral das Colônias, em 1943, com o seguinte e sugestivo título O significado do governo de Ferreira do Amaral em Macau.

\section{HERÓIS NACIONAIS NO ESTADO NOVO}

Segundo Arlindo Manuel Caldeira (CALDEIRA, 1995, p. 123124), a exaltação dos heróis nacionais em Portugal adviria dos tempos que antecederam a fundação da República, quando se percebeu o quanto os mitos poderiam ser aliados aos interesses de uma restauração do ânimo português diante da decadência econômica e política da monarquia, tanto no cenário interno quanto no externo. Tornou-se, daí, prática comum do estado português a recuperação da memória para efeito de propaganda. A República, seguida pelo Estado Novo, criou a sua própria mística ao pretender uma refundação nacional. Data desta época o surgimento da noção de "portugalidade", a partir da qual narrativas sobre o passado e o próprio passado converteram-se em mitos nacionais, como bem aponta Eduardo Lourenço (1991), circunstanciados pelas sucessivas ideologias políticas, fossem liberais, democráticas ou fascistas. No caso do Estado Novo, a propaganda apossou-se dos mitos, dando-lhes ordem e sentido a fim de celebrar o pacto político do estado com o imaginário nacional. Ao serviço do estado, os heróis nacionais, agentes dos mitos nacionais, ao serem exaltados, recuperariam alguma autoestima perdida durante os períodos anteriores e ofertariam sentido à posteridade. 
Uma das formas mais correntes de submeter a História à ideologia oficial, durante o Estado Novo, era o recurso à tradição, expressão vaga, porém funcional, e o seu consequente estímulo, que garantia uma continuidade imediata entre o passado histórico exaltado e a experiência cotidiana de qualquer português. Essa continuidade envolvia desde os eventos históricos mais decisivos da história portuguesa até os menos reconhecidos, e, com isso, criavam uma rede fechada, e quase impenetrável, de eventos, submetidos a um único sentido, definido pelo estado. Esse procedimento interferia diretamente nos espaços privados, através, principalmente, de ações claramente pedagógicas, que, ao atuarem sobre o comportamento dos indivíduos, conformava-os a papéis sociais previamente estabelecidos e concebidos por uma particular forma de tradição, destituída, sobretudo, de qualquer possibilidade de relativizar o tempo presente. Assim, o estado estimulou práticas que promovessem aquela forma de tradição, fosse pelas artes (literárias, plásticas e visuais), fosse pelo folclore - e esta tradição, para além das práticas folclóricas, consistia indubitavelmente na História como reexperimentação cotidiana, como se verifica no antológico "Discurso de Braga" (1936) e na não menos antológica coleção de painéis pedagógicos denominados “A Lição de Salazar” (1938).

Nessa altura, durante os anos da vigência da chamada "política do espírito". a História de Portugal passou a ser formulada como uma escrita memorialística, revestida de capa historiográfica. Inscrevia-se no cotidiano e não estabelecia um distanciamento necessário para ser concebida enquanto História. Por esta convivência íntima entre Memória e cotidiano não foi difícil que uma mitologia nacional fosse concebida para ordenar, reger e substancializar a Memória. Contudo, não era possível lançar mão da Memória diretamente; mesmo que se recuperasse o patrimônio artístico e cultural, mesmo que se valorizassem as obras literárias tradicionais ou se constituísse uma nova literatura submetida aos interesses do estado, era imperioso impor à Memória um sentido prévio e que a colocasse sob o controle do estado.

Arlindo Caldeira ainda chama a atenção para o fato de que, apoiada sobre efemérides e episódios heroicos, a História portuguesa impunha uma noção descontínua do tempo, porque lançava sombra por sobre os períodos intermediários entre efemérides e porque instituía um calendário baseado nas mesmas efemérides. Assim, os heróis não só punham apenas em sua função a Memória portuguesa, mas também a própria noção de temporalidade e, consequentemente, de cronologia, porque o tempo era contado a partir das celebrações nacionais que ofereciam sentido à portugalidade.

Por outro lado, a transposição do passado para o presente também foi levada a cabo ao interferir na noção de espacialidade e territorialidade, na medida em que se amalgamavam nacionalismo e colonialismo. Os espaços coloniais eram peça fundamental para o sucesso do projeto estadonovista e, por isso, era necessário atrair o máximo da atenção nacional para a empresa colonial - assim, o Império convertia-se em extensão do estado e da nação. 
O elenco de heróis celebrados pelo Estado Novo era vasto, cobria os oitocentos anos da História portuguesa e toda a extensão espacial do Império. Imaginariamente compreendido, o Império comparecia discursivamente como uma articulação espaço-temporal porque era considerado em toda a sua extensão histórica, ou seja, o Império não era apenas os territórios efetivamente controlados, o Império era também os espaços onde os portugueses se teriam fixado em algum momento de sua História. Dessa forma, o discurso imperial reivindicava o Brasil ou outras terras espalhadas pela África ou Ásia como partes integrantes desse espaço-tempo imaginário. Ao verificarmos os heróis celebrados, estes correspondiam exatamente a essa perspectiva na medida em que são encontradas, por exemplo, várias referências aos homens que se destacaram na exploração e expansão na América, na luta contra a dominação holandesa no nordeste brasileiro, ou nas guerras de independência do Brasil, ou, ainda, na campanha de Afonso de Albuquerque, no estreito de Ormuz, ou na conquista de Malaca.

A vasta plêiade de personagens históricos construía um elenco de modelos célebres. Desses, destaca-se a figura de Mouzinho de Albuquerque que, celebrado em mais de quatro biografias publicadas pela AGC, foi convertido, especialmente entre os anos de 1936 e 1947, em paradigma maior da colonialidade e do Império. Característicos da fase imperial do Estado Novo, esses modelos foram cedendo lugar a outros mais integrados a uma perspectiva luso-tropicalista, na qual os mestiços passariam a um protagonismo mais evidente, sem, no entanto, deslocar o paradigma do homem branco colonizador - e isso sem afetar o discurso oficial, que paulatinamente abandonou a constância das efemérides imperiais.

\section{MACAU E FERREIRA DO AMARAL PELO IMPÉRIO}

Macau apresenta-se como um espaço singular para o colonialismo dos séculos XIX e XX, já que não poderia de maneira alguma ser comparado à maior parte das possessões coloniais europeias, tendo tido relativa autonomia diante de sua metrópole. Por fim, Macau destaca-se, ainda hoje, no conjunto de territórios um dia controlados pelo Império, como efetivo espaço de disputa por sua memória em tempos pós-coloniais. ${ }^{8}$

A atenção aos espaços coloniais por parte da produção editorial da Agência Geral das Colônias (AGC) era bastante desigual. Nesse panorama, destacam-se Angola e Moçambique como colônias privilegiadas, seja pela publicação de informes e artigos no Boletim da AGC ou em O mundo português, seja nas diversas coleções editadas e publicadas pela Agência durante sua existência. Autores nascidos ou localizados em Macau que publicaram no Boletim da AGC, segundo a investigação de José Luís Lima Garcia (GARCIA, 2011, p. 465), foram 1\% do total de mais de quatrocentos autores que nele publicaram durante a existência daquele órgão oficial de divulgação colonial. Da mesma maneira, a quantidade de artigos publicados no Boletim em que Macau foi tema de fundo é também mínima. No Catálogo Bibliográfico da Agência Geral das Colônias, de 1943, figuram, entre cerca de quatrocentos e cinquenta títulos publicados pela AGC, apenas doze obras publicadas com temas relativos a Macau. 
Na coleção "Pelo Império", publicada entre 1935 e 1961, encontra-se apenas um título dedicado a Macau, especificamente $O$ significado do governo de Ferreira do Amaral em Macau, 1846-1849, de Lia A. Ferreira do Amaral (1944). A coleção era destinada, principalmente, às bibliotecas escolares, na metrópole e nas colônias, e, por isso, sua função pedagógica era acentuada na medida em que contemplava biografias de vultos da história colonial portuguesa. Essas biografias tinham um claro tom celebrativo e um excessivo pendor nacionalista que se convertia imediatamente na adesão ao colonialismo pelo esforço demonstrado pelo personagem histórico para manter e perpetuar o império colonial. Nessa coleção, Mouzinho de Albuquerque foi o paradigma mais exaltado, representado por duas biografias distintas e, pelo menos, por três outras obras sobre as campanhas militares em Moçambique ao fim do século XIX. Dessa maneira, a personalidade cuja biografia fosse contemplada pela coleção, ou, mesmo, o evento narrado, era alçada à condição de herói, digno de honras e culto por toda nacionalidade.

A narrativa biográfica de Lia A. Ferreira do Amaral, constitui-se marco, tanto na coleção "Pelo Império", quanto no conjunto de publicações da AGC. Seja porque pode demonstrar o lugar diminuto ocupado na política colonial pelo território asiático, como, também, inserir-se na perspectiva literária estreita, a respeito da ação colonial, disponível naquela altura no conjunto de publicações promovidas pela AGC. Numa tentativa biográfica, a bisneta de Ferreira do Amaral dá forte contorno dramático à narrativa, conferindo atributos heroicos ao antepassado mesmo antes de sua nomeação para o governo geral do território asiático. Acentua-lhe a participação na campanha militar portuguesa quando da Independência da Bahia, em 1823, que custou a Ferreira do Amaral a amputação de um braço, mas que lhe garantiu a notoriedade e a condecoração como herói militar. Vale reproduzir o episódio da amputação, onde o antepassado da autora tem exaltadas características de hipermasculinidade, atributo mais do que necessário para a consolidação e manutenção do Império:

Sofre a operação sem um gemido, fumando um charuto, sentado numa cadeira de braços. As pessoas que assistem empalidecem, calculando as dores que ele deveria sofrer. Amaral, vendo cair o braço, levanta-se da cadeira e, atirando com ele ao ar, exclama: "Viva Portugal!!!". Em seguida, dirige-se para a tolda do navio e anima os seus camaradas. (AMARAL, 1944.p. 37-38).

A narrativa, apesar de simplória, tanto sob o ponto de vista literário, quanto do ponto de vista historiográfico, sustenta-se sobre o ideário do Estado Novo, no qual Portugal, e seu império encontram-se em permanente perigo de fragmentação, destroçamento e destruição. A biografia dá ênfase ao período de exercício do governo de Macau (1846-1849) e é antecedida por notas históricas sobre Macau e sucedida pela transcrição das duas últimas cartas enviadas por Ferreira do Amaral à família, datadas de junho de 1849. Essas duas cartas, no entanto, dão à pretensiosa obra o seu claro tom memorialístico, já que, apesar de dirigidas à família, fazem o interlocutor atravessar a posteridade e ganhar um estatuto coletivo. Os pla- 
nos administrativos do governador, aliados a um claro tom empreendedor, fazem das missivas uma espécie de mensagem para o presente da publicação, o futuro (1944), visto que o sucesso da administração portuguesa em Macau, durante o Estado Novo, se devia à herança "da firme administração de Ferreira do Amaral" da qual resultara o tratado sino-português de 1887. Além disso, a biógrafa insiste em fazer da atuação do biografado a metonímia da história portuguesa dos séculos XIX e XX, já que a biografia composta por Lia Ferreira do Amaral presentifica seu antepassado ao reconhecer-lhe o estatuto de herói nacional, cuja administração colonial teria previsto as relações, no presente de então, entre a metrópole e suas possessões coloniais.

\section{O ASSASSINO}

Retomando a narrativa de Tang e contrastando-a à biografia de Amaral, fica clara a problematização que a narrativa literária impõe ao discurso colonial, que salta das páginas da descendente do governador. Isso porque, em Tang, Amaral é destituído da condição de agente histórico, pelo contrário, é objeto submetido à política chinesa e às suas relações com Império Britânico. Portugal e suas pretensões colonialistas ficam reduzidos ao evento histórico do crime. $\mathrm{O}$ assassino, que dá título à narrativa, emerge como o protagonista possível sob outro olhar que se desvia dos "grandes feitos" heroicos do passado e que hoje reclamam seus direitos de existência pela memória. Nesse caso, $O$ assassino parece cumprir a perspectiva de Walter Benjamin que confere à literatura o lugar de fixação dos discursos dos vencidos - apesar de agente de um crime político, o assassino nada representa, é o espectador do jogo jogado pelas potências em embate histórico. A narrativa de $O$ assassino, contradizendo a fala da História, converte-se em memória e busca, sobretudo, libertar o passado dos discursos que o controlam, propondo a sua enunciação e a sua consequente dispersão entre aqueles que foram apenas peões de outros jogadores. É a reivindicação de uma História de perfil democrático e plural, na qual todos os discursos podem convergir e divergir, para além das potências imperiais e coloniais.

\section{REFERÊNCIAS BIBLIOGRÁFICAS}

ALVES, Ana. Macau: Uma ponte entre a China e os países africanos de língua oficial portuguesa. Revista Administração - Macau (Direcção dos Serviços de Administração e Função Pública), 69 (18), 2005: 163-1173.

AMARAL, Lia Arez Ferreira do. O significado do governo de Ferreira do Amaral em Macau: 1846-1849 [Pelo Império. 105, 106]. Lisboa: Agência Geral das Colónias, 1944. 2v.

BRAY, Mark; KOO, Ramsey. Postcolonial patterns and paradoxes: language and education in Hong Kong and Macao. Comparative Education, 40 (2), 2004: 215-239. Disponível em: http://educ2.hku.hk/ bray/ Bray\&Koo_HK-Macao2004.pdf. Acesso em 08/10/2015. 
CAHEN, M. e outros. Issues of Asian Portuguese-Speaking Spaces and Lusotopias. Lusophonies asiatiques, Asiatiques en lusophonies, Lusotopie: Enjeux Contemporaines dans les Espaces Lusophones. Paris, Éditions Karthala, 2000. p.137-158.

CALDEIRA, Arlindo Manuel. O poder e a memória nacional: heróis e vilãos na mitologia salazarista. Penélope, fazer e desfazer a história, 15, 1995: 121-139.

CHAN, Ming K. "Different roads to Home: the retrocession of Hong Kong and Macau to Chinese sovereignty". In: Journal of Contemporary China, 12, 2003: 493-518. Disponível em: http://www.olemiss.edu/courses/ pol324/chan03.pdf. Acesso em 28/09/2015.

CHENG, Christina Miu Bing. Macau. A Cultural Janus. Hong Kong: University Press, 1999.

DAN, Wei (coord.). Os Países de Língua Portuguesa e a China num Mundo Globalizado. Coimbra: Almedina, 2009.

HAI, Wang. Macau: plataforma de intercâmbios internacionais e inter-culturais para a China na Era da Globalização". In: Revista Administração - Macau (Direcção dos Serviços de Administração e Função Pública), 74 (19), 2006: 1381-1411.

HUYSSEN, Andreas. Seduzidos pela memória. 2. ed. Rio de Janeiro: Aeroplano/ UCAM/ MAM-RJ, 2000.

GRANJA, Rosemary da Silva. Varões assinalados: o tema do homem moderno na epistolografia de Antero de Quental (Dissertação de Mestrado). Niterói: Pós-Graduação em Letras / UFF, 2003. Or. Mário César Lugarinho.

LOURENÇO, Eduardo. O labirinto da saudade: psicanálise mítica do destino português. 4a ed. Lisboa: Dom Quixote, 1991.

QUENTAL, Antero de. Causas da decadência dos povos peninsulares. 6a ed. Lisboa: Ulmeiro, 1994.

. Cartas II. [Obras Completas, v. 7]. Org. intr. e notas de Ana Maria Almeida. Lisboa: Universidade dos Açores/ Editorial Presença, 1989.

SALAZAR, António de Oliveira. Discursos (1935-1937), v. 2. 2aed. Coimbra, Coimbra, 1945.

SIMAS, Mônica. Podem os macaenses falar? Da subalterna à condição especial. Cadernos de Literatura Comparada (FLUP), 1, 2013: 21-41. Disponível em http://ilc-cadernos.com/index.php/cadernos/article/view/162. Acesso em 14/09/2015.

TANG, Joe. O assassino. Macau: Praia Grande, 2015. 


\section{NOTAS}

1 Professor Associado da Universidade de São Paulo. Doutor em Letras (Puc-Rio, 1997)e Livre-docente (USP, 2012). Realizou estágio de pós-doutoramenteo no Centro de estudos comparatistas da Universidade de Lisboa (2012-2013) e foi "visiting scholar" na Universidade de Macau (2015-2016). Publicou Manuel Alegre: mito, memória e utopia (Lisboa, 2012) e Uma nau que me carrega: rotas da literariedade em Língua Portuguesa (Manaus, 2013). É bolsista de produtividade do CNpq, desde 2001.

2 Entre 1845 e 1974, a autoridade decisória do Leal Senado de Macau foi exercida pelo governador geral, nomeado diretamente por Lisboa. O Leal Senado, que servia de câmara municipal, foi, desde a sua fundação, em 1583, a principal instância administrativa do território reconhecida pelos governos chinês e português.

3 Handover foi como ficou conhecida a data de 20 de dezembro de 1999, quando a soberania de Macau foi transferida de Portugal para a China.

4 Questões como essas aparecem continuamente na imprensa macaense e em debates públicos promovidos pela administração do território e nas universidades locais. O patrimônio cultural português deixado em Macau, nomes de logradouros, monumentos históricos, culinária, amistosas relações diplomáticas do território com Portugal, é potencializado por uma agressiva política de divulgação da língua portuguesa mantida pela administração central de Macau. Além disso, o governo de Pequim incentiva o estatuto especial de Macau junto aos países da CPLP, tornando-a polo atrativo de ações culturais e econômicas.

5 Informações e reflexões mais apuradas acerca da cultura macaense, sua identidade cultural e ações da administração central no que tange às relações exteriores com os países de língua portuguesa, v. ALVES (2005), BRAY (2004), CAHEN (2000), CHAN (2003), CHENG (1999), DAN (2009), HAI (20006), SIMAS (2013).

6 Também a música se voltou para aquele episódio histórico. Em junho de 2014, a Ópera de Pequim apresentou a A alma de Macau, de Wu Xiaoping, ópera chinesa, em mandarim, em dois atos, na qual apresenta também versão sobre o assassinato do governador, no qual o protagonismo é desempenhado por Sheng Zhiliang, o homem condenado pelo assassinato do governador português. Segundo Mok Ian Ian, o libretista, a ópera trata do "sonho chinês", isto é, viver uma vida pacata e autônoma, o que estava comprometido pela presença do governador em Macau, bem como pela disputa da hegemonia econômica no território. Mais informações em https://www.macaomagazine.net/history/dramatic-history.

7 Num estado monárquico decadente, que carecia de sustentação na vida cotidiana da burguesia emergente, exemplos de heroísmo e nacionalismo eram fundamentais à sua sustentação, como se verifica, por exemplo, em passagens da famosa Causa da decadência dos povos peninsulares, de Antero de Quental - reflexão reafirmada em carta a Alberto Osório de Castro, de 25 de novembro de 1890, Antero escreve: "Portugal é um país eunuco, que vive duma vida inferior, para a vileza dos interesses materiais (...)" (QUENTAL, 1989, p. 1013, carta 652). Para mais informações a respeito da demanda portuguesa por heróis e homens valorosos no século XIX v. GRANJA (2003).

8 Assim como a obra de Tang e a já citada ópera questionam o destino do território, a obra cinematográfica A última vez que vi Macau (2012) também se dedica a questionar não apenas a atual memória da presença portuguesa no território, mas, também, o seu destino. O filme estabelece diálogo direto com a produção da RKO Pictures Macao (1952), recorrendo a takes, trilha sonora, indumentária e cenários semelhantes, porém, atualizados.

9 Das diversas publicações da Agência geral das Colônias, a coleção "Pelo Império" se destaca pela sua amplitude ambiciosa e pelos objetivos já que "largamente espalhada pelo meio escolar, recorda à mocidade de hoje o que fizeram os homens que no passado ergueram tão alto o nome de Portugal" segundo Julio Cayolla, Agente Geral das Colônias (1939-1946). A coleção entrou em declínio depois do afastamento de Júlio Cayolla da direção da Agência (1946), tendo sido encerrada em 1961. 